\title{
The Biodiversity Heritage Library: sharing biodiversity literature with the world
}

Nancy E. Gwinn

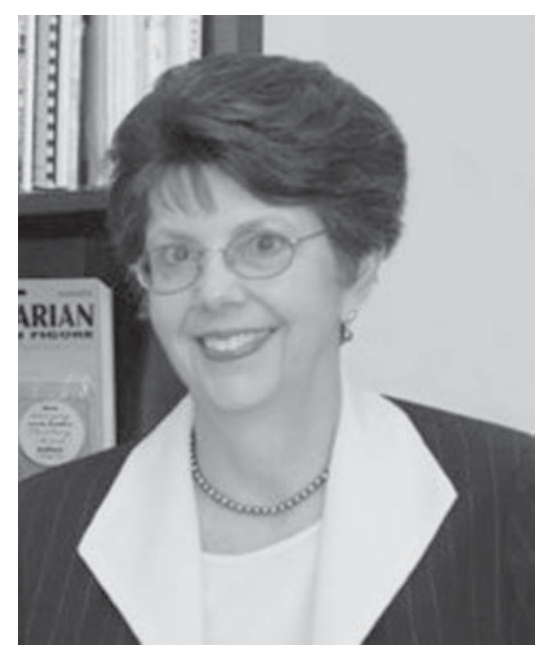

Constance Rinaldo

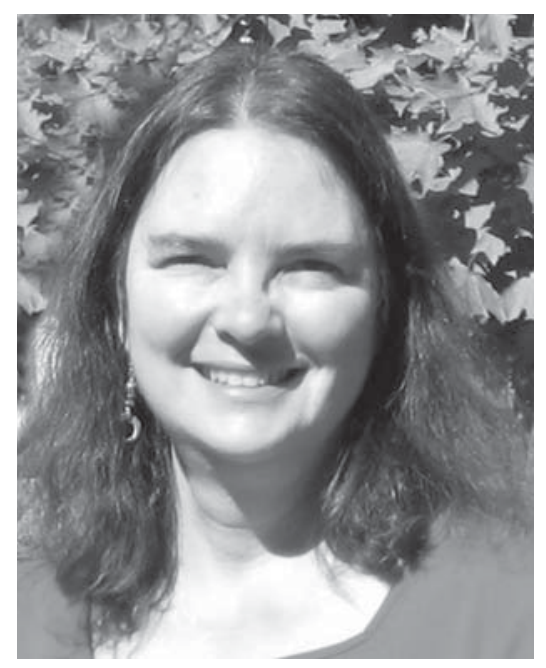

\begin{abstract}
Ten major natural history museum libraries, botanical libraries, and research institutions in the United Kingdom and the United States joined in 2005 to develop a strategy and operational plan to digitize the published literature of biodiversity held in their respective collections and to make that literature available for open access and responsible use as a part of a global 'biodiversity commons.' Headquartered at the Smithsonian Institution Libraries, the Biodiversity Heritage Library (BHL) is one of the cornerstones of the Encyclopedia of Life, a global effort to document all 1.8 million named species of animals, plants, and other forms of life on earth. This paper provides an overview of the BHL and its potential impact on biodiversity research, describes the BHL portal and its innovative search services, and provides a case study of the process from one of the members: the Museum of Comparative Zoology at Harvard University.
\end{abstract}

Keywords: Biodiversity Heritage Library; Smithsonian Institution Libraries; Museum of Comparative Zoology; Harvard University; taxonomy; systematics

\section{Introduction}

According to a US government report, biodiversity, a term coined by internationally renowned scientist E.O. Wilson as a shortened form of 'biological diversity', refers to the variety and variability among living organisms and the ecological complexes in which they occur. ${ }^{1}$ The basic sciences to identify biological diversity are known as taxonomy, the theory and practice of describing, naming, and classifying all plants, animals, and microorganisms of the world, and systematics, the classification of living things into groups based on their evolutionary origins. Research in these disciplines is most often conducted in natural history museums and botanical gardens in the developed world, which contain rich and extensive collections of flora and fauna, as well as large libraries of the literature that document them. Taxonomists have barely scratched the surface of known species (Godfray 2007; Wheeler 2008). It is estimated that there are between 5 and 30 million species on the planet, yet only 1.8 million have been identified and described.

In 1992, 150 government leaders signed the Convention on Biological Diversity, which recognized the crucial role of taxonomy in promoting sustainable development. For several years, taxonomists have recognized the need to speed up their work, before expanding populations, environmental calamities, and economic development reduce the wealth of existing species. Their work has value well beyond the act of identification; it has wide use and economic impact for a broad range of applications in agriculture, biodiversity conservation, protected area management, control of invasive species, forestry, plant breeding, disease control, and trade in natural products, including pharmaceuticals (Wheeler 2008). Yet there are severe obstacles to progress, what the field has termed the 'taxonomic impediment.' Taxonomists largely carry out their 
work among the specimen and literature collections in the industrialized nations. There are few taxonomists to collect and work on the millions of undescribed species in biodiversity-rich but economically poorer countries. ${ }^{2}$ And for all taxonomists, access to the relevant literature can be a costly, time-consuming process (Godfray 2007; Minelli 2003).

More than any other science, the domain of systematic biology is utterly dependent on the historical literature of published descriptions of species; publication in print still determines the legitimacy of naming and credit for new discoveries. Allessandro Minelli writes:

According to current practice, any serious monographic work about a given taxon should include a careful consideration of all previous literature dealing with at least one species belonging to that taxon, regardless of whether it was published last year or in the late 18th century, whether it is written in English or in Spanish, in Russian, or in Latin. If these works include the description of (the then) new taxa, or have an impact on its nomenclature, they cannot be ignored. ${ }^{3}$

Minelli describes taxonomic papers as 'legal' documents as well as scientific ones, because they describe new species according to rules of distinct international codes. ${ }^{4}$ The codes exist to ensure that all taxonomists adhere to principles of priority, which resolves problems caused by the use of homonyms or synonyms in naming. Consequently, taxonomists must consult all relevant literature from Linnaeus ${ }^{5}$ onwards to ensure a sound basis for their work.

Technology and the Internet finally provided a way to dissolve the taxonomic impediment, at least in part, through scanning of both the literature and specimen collections so they can be shared with the global scientific community (Godfray 2007). There are over 5.4 million volumes on biodiversity dating back to 1469: 800,000 monographs and 40,000 journal titles. Fifty percent were published before 1923 and are in the public domain in the United States. It is a big job.

\section{Planning Begins}

In 2003, the Smithsonian Institution hosted a conference of biologists to discuss what was needed to improve the efficiency of biological research. The greatest obstacle, experts determined, was access to the historical literature (see Figure 1 for an example). Those of us in natural history museum and botanical garden libraries know that for years, researchers have traveled to use our collections, often spending most of their time standing in front of photocopy machines to collect as much literature as possible before they returned home. Digital technology and the Internet offered a solution; if the literature was scanned and made searchable on the web, researchers could gain access from wherever they were in the world. As a result of the conference, the Smithsonian provided funding for the Smithsonian Libraries to digitize the Biologia Centrali-Americana, a 63-volume work published from 1879-1915, which remains the seminal work on the flora and fauna of Central America. ${ }^{6}$ The funding also supported initial work toward developing a system of automatic coding of the scientific names of species found in the work to improve accessibility for taxonomists.

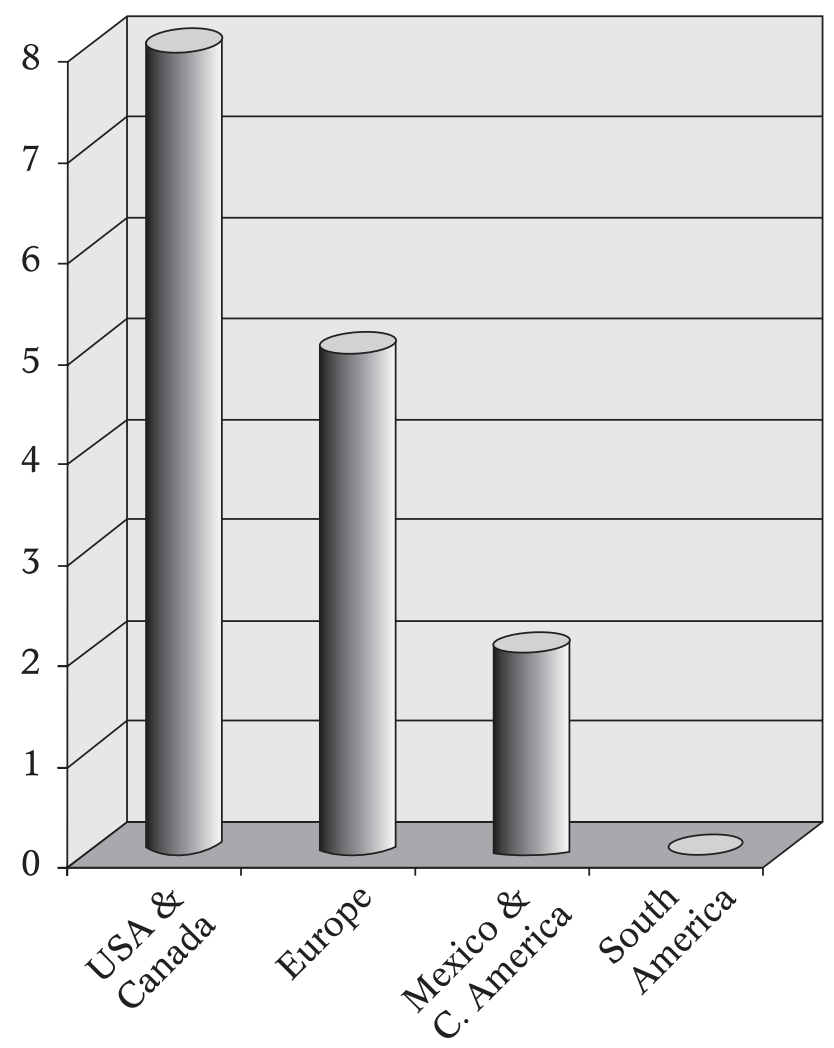

Figure 1. Distribution of copies of the Biologia Centrali-Americana; the copies in Central America are located in the Earl Tupper Library, Smithsonian Tropical Research Institute, Republic of Panama, one of the Smithsonian Libraries' twenty branch libraries. Courtesy, Martin Kalfatovic. 
In 2005 at the Natural History Museum in London, the Alfred P. Sloan Foundation funded an international symposium called Library and Laboratory: the Marriage of Research, Data, and Taxonomic Literature. The 80 biologists, librarians, and computer scientists who attended again identified the lack of access to the published literature of biodiversity as one of the principal obstacles to efficient and productive research (Moritz 2005).

In May 2005, representatives of several major natural history and botanical libraries met at the Smithsonian's National Museum of Natural History in Washington, DC. With funding provided by the Smithsonian Institution, the goal of the meeting was to develop a strategy and operational plan to digitize the published literature of biodiversity held in their respective collections and to make that literature available for open access and responsible use as a part of a global 'biodiversity commons' (Moritz 2002). Two years later, the directors of the libraries of the American Museum of Natural History, Harvard University Botany Libraries, Harvard University Ernst Mayr Library of the Museum of Comparative Zoology, Missouri Botanical Garden, Natural History Museum in London, New York Botanical Garden, the Royal Botanic Gardens, Kew, Field Museum of Natural History in Chicago, Marine Biological Laboratory/Woods Hole Oceanographic Institution Library and the Smithsonian Institution Libraries agreed to a Memorandum of Agreement that established the Biodiversity Heritage Library (BHL). ${ }^{7}$ The Smithsonian Libraries agreed to host the BHL Secretariat and provided from its senior management staff the first Program Director, Thomas Garnett.

Another development was brewing at the same time, the Encyclopedia of Life. ${ }^{8}$ This is an ambitious, even audacious, collaborative global project to document authoritatively the 1.8 million known species of animals, plants, and other forms of life and to create web pages on the Internet for each one. Each page is just an entry point, suitable for the general public but with linked pages pointing to more specialized data for researchers. The Encyclopedia embraced the Biodiversity Heritage Library as one of its four cornerstones, to bring much of the historical literature about a species to the relevant web page. This was critical for the project, because through the Encyclopedia of Life, the BHL received a first increment of USD 3 million from the John D. and Catherine T.
MacArthur Foundation. Additional funds have come from the Alfred P. Sloan Foundation, the Gordon and Betty Moore Foundation, the Richard Lounsbury Foundation and individual BHL member institutions.

\section{Why Do This Now?}

The ten BHL member libraries have over 2 million volumes of biodiversity literature collected for over 200 years to support scientists and students throughout the world. Clearly these libraries together hold a substantial part of the world's published knowledge on biological diversity. While there are several mass digitization projects at major research libraries here and abroad, none have the discipline-specific focus of the BHL partner institutions and may fail to capture significant elements of this biodiversity legacy. Much of the biodiversity literature is highly specialized and often not duplicated even in broad university research collections. Nor are all of them allowing open access to the digitized publications. With its innovative search strategies, the BHL is intended to be 'one-stop shopping' for those needing to consult biodiversity literature.

Costs of scanning have fallen considerably and in a high-production mode, the Internet Archive projects a low basic cost of 10 cents a page. The biodiversity literature is a tractable, well-defined scientific domain and has extreme longevity current taxonomic literature often relies on texts and specimens that are more than 100 years old. (Godfray 2007; Minelli 2003) In addition, the BHL supports the Global Biodiversity Information Facility (GBIF) and other international biodiversity initiatives ${ }^{9}$ (Speers and Edwards 2008). The benefits are clear: taxonomists and other scientists will have access to the biodiversity literature - globally, scientists and citizens in the developing world will finally have easy access to the historical literature. This clearly advances the objectives of the international Convention on Biological Diversity. ${ }^{10}$

\section{Getting Started}

The BHL members selected the Internet Archive to provide the scanning services and also to store the resulting digital files. The Internet Archive shares the BHL mission to provide open access 
to the literature and has the capacity to do mass scanning in a high production mode at reasonable cost. The Internet Archive began digitizing for BHL partners in early 2007. BHL members are working with three (Boston, Washington, DC, and New York) of the six ten-station Internet Archive digitization centers, as well as with smaller centers in the Smithsonian Institution, the University of Illinois, Urbana-Champaign, and the Natural History Museum, London. However, the partners are doing much more than simply scanning volumes.

Missouri Botanical Garden staff established the Biodiversity Heritage Library portal as an innovative research environment with the ambitious goal of transforming the nature of scientific inquiry, as well as vastly accelerating research in life sciences and conservation. ${ }^{11}$ Via the portal, users have access to both digitized images (JPEG 2000, PDF, and JPEG) and Optical Character Recognition (OCR) text of the literature, but that is only the start. It also employs an array of taxonomically intelligent services designed to overcome the problem of common name versus scientific name and changes of names over time. This scientific reference system for investigating scientific literature offers a model that reflects, and also serves to amplify, scientists' approaches to, and use of, the body of natural history literature.

\section{What Is Taxonomic Intelligence?}

Scientists use scientific names to find information about organisms. One organism can have many scientific names over time or multiple common names depending on language or region. Additionally, one name might refer to multiple organisms. Thus it can be difficult to retrieve information about an organism even if the current scientific name is known. This problem was addressed by an international project called uBio for Universal Biological Indexer and Organizer. uBio is composed of the Taxonomic Name Server (TNS), which acts as a name thesaurus; NameBank, a repository of over 10.7 million recorded biological names and identifiers that link those names together; and ClassificationBank, which stores multiple classifications and taxonomic concepts. ${ }^{12} \mathrm{BHL}$ uses TaxonFinder, a taxonomic intelligence algorithm developed by the collaborators at uBio, to compare the OCR texts with NameBank and identify likely scientific names (Figure 2). Once fully integrated, a researcher will then be able to search the BHL collection using any form of an organism's name (Leary et al. 2008). This will also allow users searching the Encyclopedia of Life web pages to draw in the literature related to the species.

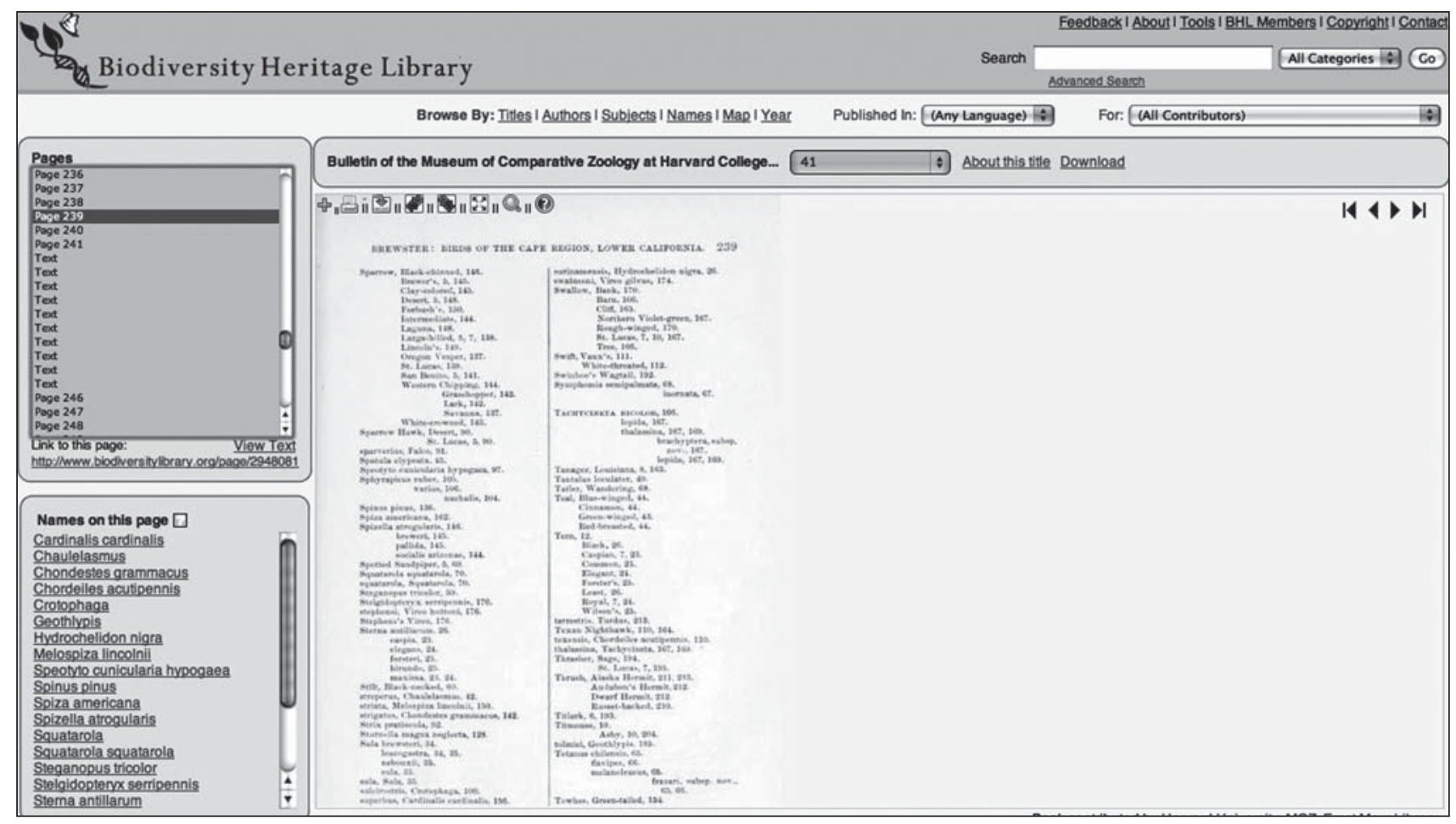

Figure 2. A page in the Biodiversity Heritage Library showing the list of scientific names (bottom left lower corner) extracted from the OCR text. 
After the Internet Archive scans the volumes, the BHL portal ingests MARCXML and other associated XML files. JPEG files are retrieved on calling up a volume and high resolution JPEG 2000 files are retrieved on the fly from the Internet Archive when requested by a user and decoded at the portal for viewing via a web browser. OCR text is also sent on the fly to uBio for name extraction via taxonomic intelligence and displayed in real time with the page image. The BHL portal serves the image and text files; displays volume, part and piece metadata; and applies Globally Unique Identifiers (GUIDs) for linking to other taxonomic services. Persistent URLs allow linking at bibliographic record, volume, and page levels in BHL. The BHL technical staff at the Missouri Botanical Garden are constantly improving the portal's presentation of results and adding features such as geocoding the Library of Congress Subject Headings using the Google Maps Application Programming Interface. .(Figure 3; Freeland et al. 2008).

The use of taxonomic intelligence to locate binomial name strings within BHL texts enables the creation of 'discovered bibliographies' related to desired taxa. Unlike traditional bibliographies or indices (e.g. Zoological Record), full-text searching of BHL content with taxonomic name recognition allows a user to find names in articles or books that traditional bibliographies did not include. BHL technical staff implemented the 'discovered bibliography' functionality that creates citation lists at the page level for taxa using the 'name find' feature.

\section{But What About Copyright?}

In general, the BHL project attempts to keep copyright infringement risk low by tackling the public domain literature first, seeking permissions for digitization, negotiating alternative agreements and moving on when none of these tactics applies. BHL has an opt-in copyright model. The BHL Program Director has opened negotiations with a variety of publishers from small, learned societies to large commercial organizations. As of December 2008, the BHL has obtained permissions to digitize 47 titles from museum and small society publishers. The BHL will digitize the entire run of the publications to the most recent issues, as per the negotiated permissions, and mount them on the BHL portal at no cost to the societies.

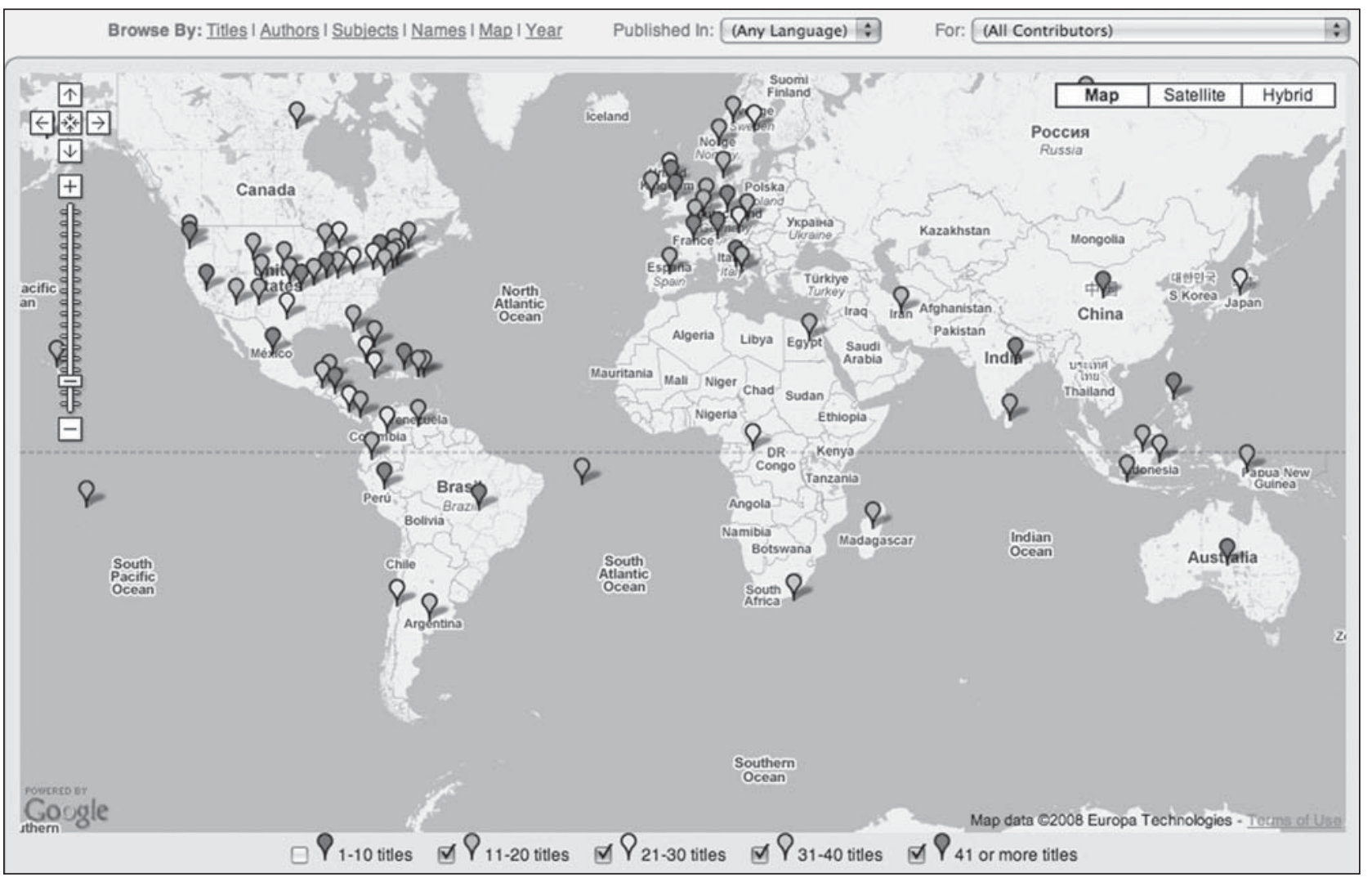

Figure 3. The Library of Congress Subject Headings of the volumes in the BHL are geocoded and then mapped using the Google Maps API. 
The files can be reused by the society for its own purposes. ${ }^{13}$ The BHL will take responsibility for long-term sustainability of the scanned material. Some aggregators and commercial publishers have expressed interest in alternative agreements, such as providing metadata and OCR files for indexing using taxonomic intelligence tools. ${ }^{14}$ Discussions are underway with the Zoological Record, BioOne, JStor and others.

\section{BHL Governance}

The Biodiversity Heritage Library is not incorporated and thus is not a legal entity. Through the Memoranda of Agreements, each member institution has committed to the collaborative effort to build the Biodiversity Heritage Library and to search for additional funding to support it. The directors of the member libraries form the Institutional Council, which provides strategic direction, reviews progress, discusses current issues, and monitors the budget. An Executive Committee meets weekly by conference call. As members have implemented the scanning process, practical issues and obstacles have appeared. The case study of the Ernst Mayr Library at Harvard's Museum of Comparative Zoology illustrates some of these.

\section{Ernst Mayr Library Case Study}

The costs of scanning, while low on a per-page basis, are high over the course of the entire project. Thus it was essential to identify ways to minimize duplication of scanning. The first step was to purchase the OCLC Collection Analysis tool and add all member library records. ${ }^{15}$ The Smithsonian Institution paid for the first year's subscription. It took more than a year to get this tool up and running, partly because not all libraries initially were members of OCLC, and, in the case of Harvard University, the records of the botany and zoology libraries could not be separated from those of the other Harvard libraries. The OCLC Collection Analysis tool enabled a broad look at institutional collection strengths and allowed the group to estimate the numbers of public domain pages that could be scanned more or less immediately and to identify subjects with unique titles in the member libraries. Non-BHL mass scanning projects have some overlap with the BHL. To minimize duplication, library staff review other projects; if the material is open access and easily ingested, in some cases, BHL members may alter scanning plans.
With input from the EOL Steering Committee, BHL members chose serial publications as the first priority, because the serial literature is critical to the scientists who make up the primary audience for the first release of the BHL. The library systems office of the Natural History Museum of London developed a tool to avoid scanning duplication among the member institutions. A mashup database was generated that included online catalog records of all the serials in all the member institutions with a checkbox for selection; thus a serials bid list was born. As titles are identified for scanning, an institution will access this database to make sure no one else has bid on the item. If there are no bids, or bids cover only part of a serials run, the institution is free to claim the title, or at least the parts of the title that have not been bid, for scanning. The MBL/WHOI Library has built a monograph de-duping tool that shows what monographs have been scanned; there is no bidding process for monographs as yet.

BHL members established a wiki early in the project to facilitate communication among the widely dispersed libraries. The wiki is used to maintain minutes of conference calls and meetings, post presentations and procedures, and coordinate technical questions, quality discussions and collections work. It became clear in March 2008 that member staff managing the day-to-day planning and processing workflows required better communication. Staff needed to compare their experiences more directly to ensure efficient workflows and to avoid 'reinventing the wheel.' Staff now participate in two or more monthly conference calls. These calls have become critical to developing and managing efficient and coordinated workflows for the BHL project. Staff in the member libraries discovered that everyone was experiencing frustration with various workflow problems and were surprised at the overwhelming amount of work to be done.

The Director of the Museum of Comparative Zoology set aside substantial funding for five years, so that the Ernst Mayr Library collections could be scanned for the Biodiversity Heritage Library. Digitization, processing and moving such a large collection is expensive in dollars and labor, so the library hired student interns to assist. Reports generated from the Mayr Library's integrated library system are used to create 'picklists' of items to pull for scanning. Picklists are lists of items available to scan, based on date criteria, in shelf-list order and simplify the process of pulling 
exactly the right items from the shelves. All items are barcoded and cross-checked for suitability for scanning; fold-outs are identified, measured and flagged. Picklists are edited upon checking the holdings of BHL partner institutions using tools described above to minimize duplication of scanning effort. Staff generate a final packing list for each shipment to the scanning center once individual items have been checked for scanning suitability based on size, fragility and size of foldouts. A database contains an inventory of all items scanned for the Ernst Mayr Library. Items rejected, either by the Library or the scanning center, are tracked via the integrated library system.

It takes a minimum of 2.5 staff to keep the project moving at a pace of about 200 books every other week.. Harvard's systems staff work with the Internet Archive to ensure smooth Z39.50 connections and help with project planning and problems.. The Z39.50 connection enables the Internet Archive to pull metadata from the Harvard University catalog to populate the Internet Archive and BHL portal records. Ultimately, it is important that Harvard users have immediate access to the digital collections and thus the final step is to provide access to digitized material through Harvard's portal.

Many of the early publications have fold-outs or are larger than average size. Initially, the Internet Archive had strict limits on size and did not scan books with fold-outs. Other issues that cause

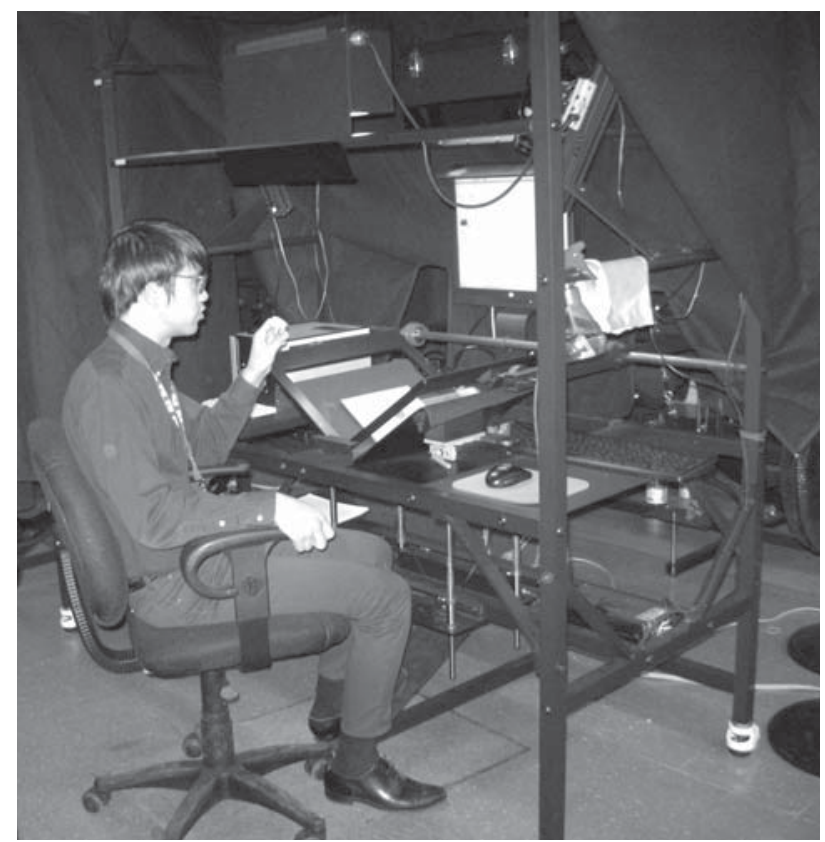

Figure 4. One of the Internet Archive scanning stations at the Boston Public Library. rejection or questioning of items for scanning include tight margins, size, brittleness and poor binding. Internet Archive personnel in the Boston scanning center (Figure 4) have been flexible and are willing to scan unusual items and provide test scan samples so that the best decision for the library's materials can be made. A solution to the fold-out problem is being tested in Boston and although there is still a size limit ( 18 by 24 inches), it is an exciting improvement (Fig 5). The quality of the scanned foldouts varies; some are superior to the original, some as good as the original, and some are inferior to the original but adequate for display. To see the best quality foldouts, the JPEG 2000 image must be viewed. The pdf and other views of the foldouts are not adequate in most cases. Fewer books are rejected now because of fold-outs, but digitizing them increases scanning time and thus the cost.

\section{Results to Date}

As of December 2008, there were more than 10.3 million pages, contained in nearly 8,760 titles (more than 25,000 volumes) accessible through the BHL portal. The project has demonstrated that: the concept of mass scanning of general collections is possible; there are high levels of OCR accuracy in late 19th and 20th century printing. The taxonomic intelligence (species name finding) across millions of pages against nearly 11 million names in Name Bank is highly effective. Administratively separate and geographically disparate institutions can collaborate on a complex, multilevel project and achieve concrete results in a specific knowledge domain.

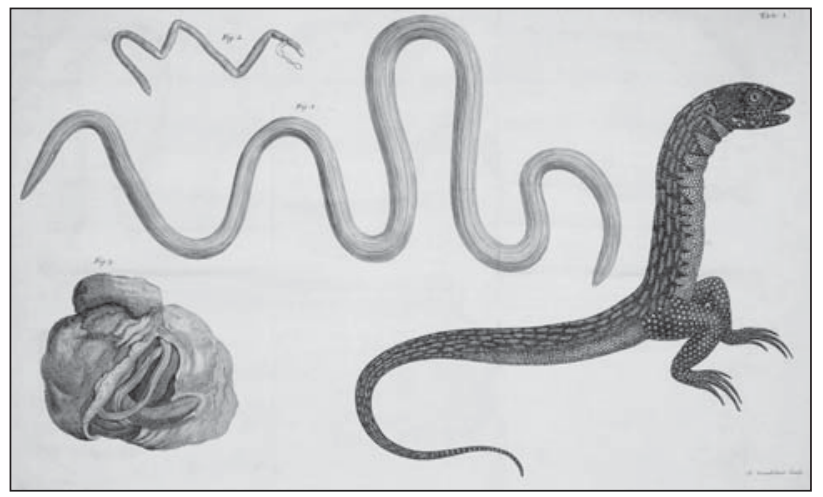

Figure 5. A sample fold-out from Klein, Jacob Theodor. 1755. Tentamen herpetologiae. Leidae \& Gottingae : Apud Eliam Luzac, Jun.

The original foldout was $10^{\prime \prime}$ by $15^{\prime \prime}$. 
Most of the literature is in the developed world, in the Northern Hemisphere, but as mentioned earlier, most of the biodiversity is in the developing world and the Southern Hemisphere. One of the most desirable outcomes of the project is to repatriate literature to the originating countries of publication by making it accessible to anyone with an Internet connection. That this is already working is evident from the following message that the Smithsonian Libraries received from a researcher in a natural history museum in Peru:

My deepest gratitude for allowing me access to the digital version of the very rare "Bulletin des Séances de la Société Entomologique de France". It has been very important for my work on the database of the names of the butterflies of the world to be able to consult at leisure this series, which is held by extremely few libraries in the world. I cannot stress enough the importance of having access to electronic versions of the literature, especially to us researchers who cannot benefit from well-endowed institutional libraries.... I only wish that there were many more such electronic resources. Please keep up the excellent work!

and another from Hawai'i:

Aloha. I live on The Big Island of Hawai'i, a $\$ 300.00$ plane ride away from Honolulu and the Bishop Museum. Even when I can make it to the Museum (where I study the Hawaiian Bird Skins), they do not have every single bird (moho apicalis, the Oahu moho is missing).... I have been looking for this text for over TWENTY YEARS. Mahalo nui loa for all your hard work. Reading these pages mean so much to me and many others.... I cannot thank you enough, nor stress the importance of your website enough. Thank you for putting these items on the web, and in such a findable manner.

The Encyclopedia of Life and other informatics projects are data mining the BHL for information located in the legacy taxonomic literature. The opt-in copyright model has attracted a number of learned societies, who have given permissions for digitization of current materials. Additionally the project has generated excitement in the international community and many opportunities to develop new partnerships. There has also been support from traditional bibliophile and scientific audiences.

\section{Where Do We Go from Here?}

As the case study has shown, there are problems to be solved related to scanning and the types of volumes that form the heritage literature of biodiversity. Ultimately, the project must provide 'article-level' analysis of serials, which may require some adaptation of existing bibliographic indices of biodiversity literature, as well as the development of automated tools for structural analysis. This development may be combined with the creation of the 'union catalog' to provide 'one-stop' access to the literature.

The Biodiversity Heritage Library partners are currently Anglo-American centered, though many of the collections contain extensive non-English language material. A key goal is to develop global partnerships and include a global community. The best way to incorporate more languages is to partner with other countries and have the BHL served from multiple nodes in multiple languages. The BHL is working to engage European partners through projects such as the European Distributed Institute of Technology (EDIT) ${ }^{16}$ and Synthesis of Systematic Resources (SYNTHESYS). ${ }^{\circ}$ EDIT consists of 27 European, North American and Russian institutions whose goal is to overcome the taxonomic impediment by building taxonomic expertise through training and information provision. The goal of the SYNTHESYS project is to develop a coordinated European infrastructure for researchers in the natural sciences. The BHL hopes to leverage these projects into partnerships with other countries and thus develop an infrastructure that has a non-English component. The European Union, through eContentplus, ${ }^{18}$ its program for digital libraries, has offered a large grant to a European consortium to create a BHL Europe, which will involve seventeen countries. The goal is to link this site with the existing BHL Portal. Informative discussions have also taken place already with the Chinese Academy of Sciences and in Brazil. The Australian Government is likely to fund scanning as part of the Atlas of Australian Life. The BHL will also continue to work with commercial publishers for fair and equitable use of their publications.

Linkages to other data types (e.g. molecular, morphological, phenotype) are key to the overall plan. It will also be necessary to get equal cost efficiencies and speed for special collections and items with fold-outs or that are oversized. OCR 
must improve for older publications and those in non-Roman scripts. It is likely that audiences will be expanded through social networking tools and repurposing content for new audiences. The BHL was developed primarily for scientists in partnership with the Encyclopedia of Life, but the audience will broaden as more tools become available.

The underlying architecture of BHL needs strengthening. The BHL is moving from the .Net application environment to the Fedora Commons architecture. ${ }^{19}$ Fedora Commons provides an open source architecture that can manage many forms of digital content. It will allow for an open framework for the description, storage, and retrieval of digitized materials in the different ways needed by scientists and librarians. For instance, Biologia Centralia-Americana has been described as a single title with 63 volumes or as 21 titles, each with multiple volumes. Fedora Commons can accommodate such variations and it has the potential to be a persistent, sustainable architecture for the Biodiversity Heritage Library.

The BHL partnership is working with the global taxonomic community, publishers, the Internet Archive and other organizations, to ensure that the biodiversity heritage literature is available to all, from the student seeking information on insects in the garden to scientists investigating endangered species in Brazil. It is a grand vision. But if the BHL is able to support biodiversity research by helping to eliminate one of the largest impediments to the identification of the world's living organisms, it will be counted a great success.

\section{Notes}

1. U.S. Congress. Office of Technology Assessment. 1987. Technologies To Maintain Biological Diversity, OTAF-330 (Washington, DC: U.S. Government Printing Office): 313.

2. Global Taxonomy Initiative, Convention on Biological Diversity, http://www.cbd.int/gti/problem.shtml

3. Minelli, A. 2003. The status of taxonomic literature, Trends in Ecology and Evolution, 18(2): 75.

4. These are the International Code of Zoological Nomenclature, the International Code of Botanical Nomenclature and the International Code of Nomenclature of Bacteria.

5. Carl Linnaeus (1707-1778), a Swedish botanist, physician, and zoologist, is known as the father of modern taxonomy because he developed a scheme of binomial nomenclature that is still in use today.

6. The Biologia Centrali-Americana (BCA) is a fundamental work for the study of neotropical flora and fauna. It includes nearly everything known about the biological diversity of Mexico and Central America at the time of publication (1879-1915). The original work consists of 58 biological volumes containing 1284 plates illustrating 18,587 subjects. A total of 49,392 species are described, 19,263 for the first time. Many of the illustrations and descriptions are the only ones that exist of the biota of the region.

7. About the Biodiversity Heritage Library, http://www. biodiversitylibrary.org/About.aspx

8. Encyclopedia of Life http://www.eol.org

9. Global Biodiversity Information Facility, http://www. gbif.org.

10. Convention on Biological Diversity, http://www.cbd. int/

11. Biodiversity Heritage Library, http://www.biodiversity library.org

12. About the project, http://www.ubio.org

13. Can I Use Your Images, http://www.biodiversitylibrary. org/Copyright.aspx.

14. Tools, http://biodiversitylibrary.org/Tools.aspx

15. WorldCat Collection Analysis, www.oclc.org/ collectionanalysis/default.htm

16. The European Distributed Institute of Taxonomy, EDIT, is the collective answer of 27 leading European, North American and Russian institutions to a call of the European Commission, issued in 2004, for a network in 'Taxonomy for biodiversity and Ecosystem Research.' This project started on 1 March 2006 and will last 5 years. http://www.e-taxonomy.eu

17. SYNTHESYS is the European Union-funded Integrated Infrastructure Initiative grant. This 5-year project, which began in February 2004, comprises 20 European natural history museums and botanic gardens [and] aims to create an integrated European infrastructure for researchers in the natural sciences. http://www.synthesys.info/index.htm

18. The eContentplus program expired on December 31,2008 , but will be continued after that date under the Information and Communications Technologies Policy Support Programme, one of the three initiatives that reside under the European Commission's Competitiveness and Innovation Framework Program (2007-2013). See http://ec.europa.eu/information society/activities/econtentplus/index_en.htm and http://ec.europa.eu/cip/index_en.htm.

19. About Fedora Commons, http://www.fedoracommons.org/about

\section{References and Links}

Biodiversity Heritage Library. http://www.biodiversity library.org (accessed April 23, 2008)

Biodiversity Heritage Library Prospectus. http://www.sil. si.edu/bhl/supportdocuments/BHLP-prospectus1005.pdf (accessed April 23, 2008)

Convention on Biological Diversity. http://www.cbd.int/

Encyclopedia of Life. http://www.eol.org (accessed April 23, 2008)

European Distributed Institute of Technology (EDIT). http://www.e-taxonomy.eu/

Freeland, C., M. Kalfatovic, J. Paige, and M. Crozier. (2008) Geocoding LCSH in the Biodiversity Heritage Library. The Code4Lib Journal, Issue 2. 11 pp.

Global Biodiversity Information Facility (GBIF). http:// www.gbif.org/. 
Godfray, H.C.J., B.R. Clark, I.J. Kitching, S.J. Mayo, M.J. Scoble. (2007) The Web and the structure of taxonomy. Systematic Biology, 56 (6): 943-955.

Leary, P.R, D.P. Remsen, C.N. Norton, D.J. Patterson and I.N. Sarkar. (2008) uBioRSS: tracking taxonomic literature using RSS, Bioinformatics, 23(11): 1434-1436.

Minelli, A. (2003) The status of taxonomic literature. Trends in Ecology and Evolution 18(2): 75-78.

Moritz, Thomas. (2002) Building the Biodiversity Commons. D-Lib Magazine 8 (6):

Moritz, T. (2005) Macro-economic case for open access. In: Proceedings of a Conference in Association with an International Conference on the Barcode of Life, organised by Graham Higley and Chris Lyal (Natural History Museum, London), Anna Weitzman and Tom Garnett (Smithsonian Institution, Washington), and Tom Moritz (American Museum of Natural History, New York).

OCLC Collection Analysis Tool. http://www.oclc.org/ collectionanalysis/default.htm

Speers, L, and J. Edwards. (2008) International infrastructure of enabling the new taxonomy: the role of the Global Biodiversity Information Facility (GBIF). In The New Taxonomy, The Systematics Association Special Volume Series 76, edited by Quentin D. Wheeler, Boca Raton, FL.: CRC Press, Taylor \& Francis Group, pp 87-94.

Synthesis of Systematic Resources (SYNTHESYS). http:// www.synthesys.info/index.htm

UBio. http://www.ubio.org/

United States Congress. Office of Technology Assessment. (1987) Technologies to maintain biological diversity, OTA-F-330 (Washington, DC: US Government Printing Office)

Wheeler, Q. (2008) Toward a new taxonomy. In The New Taxonomy, The Systematics Association Special Volume Series 76, edited by Quentin D. Wheeler, Boca Raton, FL.: CRC Press, Taylor \& Francis Group, pp. 1-18

Wheeler, Q. Taxonomic shock and awe. In The New Taxonomy, The Systematics Association Special Volume Series 76, edited by Quentin D. Wheeler, Boca Raton, FL.: CRC Press, Taylor \& Francis Group.

Paper presented at the World Library and Information Congress: 74th IFLA General Conference And Council, 10-14 August 2008, Québec City, Canada, in session 109. Science and Technology Libraries. Version française: http://www.ifla.org/IV/ifla74/papers/109-Gwinn-transfr.pdf

\section{About the Authors}

Nancy E. Gwinn is Director of the Smithsonian Institution Libraries. She joined the Smithsonian in 1984 as Assistant Director for Collections Management and was appointed director in 1997. A former Fulbright scholar at the University of Oxford (Linacre College) in England, Gwinn holds a BA from the University of Wyoming, an AMLS in Library Science from the University of Michigan, and a PhD in American Civilization from George Washington University. Prior to the Smithsonian, she held positions at the Research Libraries Group, the Council on Library Resources, and the Library of Congress. Formerly Chair of IFLA's Preservation and Conservation Section and of Division VI, she currently serves on the IFLA Governing Board and is Chair of IFLA's Professional Committee. At the Smithsonian, she has fostered collaborative projects with museums and archives and is a member of the Biodiversity Heritage Library Institutional Council. Nancy may be contacted at: Smithsonian Institution Libraries, PO Box 37012 MRC 154, Washington, DC 20013-7012, USA. Tel. +1 202-633-2240. Fax: +1 202-786-2866. E-mail: gwinnn@si.edu

Constance Rinaldo has been the Librarian of the Ernst Mayr Library of the Museum of Comparative Zoology at Harvard University since 1999. She received a BA in Biology and Anthropology from the University of Massachusetts at Boston, an MSc in Zoology from the University of Connecticut and an MLS from the University of Maryland. Prior to coming to Harvard, she was the Head of Collections for the Biomedical Libraries at Dartmouth College. Connie currently is a member of the Institutional Council of the Biodiversity Heritage Library and serves as the Secretary for the Executive Committee. She may be contacted at: Museum of Comparative Zoology, Harvard University, 26 Oxford St., Cambridge, MA 02138, USA. Tel.: +1 617-495-4576. Fax: +1 617-496-6838. E-mail: crinaldo@fas.harvard.edu. Website: http://library.mcz.harvard.edu 